\title{
Triguna (three qualities) personality model and two-factor conceptualization of self-compassion: a new insight to understand achievement goal orientations
}

\author{
Yogendra Verma (D) $1 \cdot A, B, C, E, F$, Gyanesh Kumar Tiwari\# $\mathbb{D}^{1 \cdot A, C, D, E, F}$, Ashutosh Pandey $\mathbb{D}^{2 \cdot C, D, E, F}$, \\ Rakesh Pandey\# (1D) $2 \cdot A, C, D, E$ \\ \#Joint senior author. \\ 1: Department of Psychology, School of Humanities \& Social Sciences, Doctor Harisingh Gour University, Sagar, Madhya \\ Pradesh, India \\ 2: Department of Psychology, Faculty of Social Sciences, Banaras Hindu University, Varanasi, Uttar Pradesh, India
}

BACKGROUND

Although the three-dimensional Vedic personality model (Triguna) and self-compassion have been linked with a variety of life outcomes, little is known about their interplay in shaping goal orientations. We explored the interrelationships and interplay of the Triguna (Sattva, Rajas and Tamas) with positive and negative self-compassion in shaping the goal orientations of Indian students.

\section{PARTICIPANTS AND PROCEDURE}

Using convenience sampling, 190 males $(M=20.13, S D=2.21)$ and 187 females $(M=19.88, S D=1.81)$ were assessed on selfreport measures. Data were analysed using correlational statistics, factor analysis and path analysis.

\section{RESULTS}

Factor analyses supported our speculation that the SelfCompassion Scale is best represented by a two-factor model (positive and negative). Positive self-compassion and Sattva Guna showed positive correlations with mastery and performance goals while negative self-compassion showed an opposite pattern. Rajas and Tamas Gunas were negative- ly correlated with mastery and positively with performance goals. Gender, Sattva Guna and positive self-compassion accounted for significant variance in mastery while gender, Sattva and Rajas Gunas and negative self-compassion contributed to performance-approach. Sattva Guna and selfcompassion (positive and negative) contributed significantly to performance-avoidance. Path analysis revealed direct as well as indirect effects of the three Gunas on the goal orientations through positive and negative self-compassion.

CONCLUSIONS

The Triguna personality and two-factor conceptualization of self-compassion evinced their relevance in understanding the goal orientations of Indian students. Re-conceptualization of the Self-Compassion Scale and its interplay with Triguna personality dimensions in shaping the goal orientations of students need further verification in diverse and cross-cultural populations.

\section{KEY WORDS}

Triguna personality; positive and negative self-compassion; mastery; performance-approach; performance-avoidance

Corresponding Author - Gyanesh Kumar Tiwari, Ph.D., Department of Psychology, School of Humanities \& Social Sciences, Doctor Harisingh Gour University, Sagar 470003, Madhya Pradesh, India, e-mail: gkt@dhsgsu.edu.in AUthors' CONtRibution - A: Study design - B: Data collection - C: Statistical analysis - D: Data interpretation .

E: Manuscript preparation · F: Literature search · G: Funds collection

to cite this article - Verma, Y., Tiwari, G. K., Pandey, A., \& Pandey, R. (2020). Triguna (three qualities) personality model and two-factor conceptualization of self-compassion: a new insight to understand achievement goal orientations. Current Issues in Personality Psychology, 8(3), 211-228. 


\section{BACKGROUND}

Self-concept plays a vital role in shaping a multitude of life outcomes for people of all age groups. A variety of self-constructs have been proposed by researchers to understand and explain the performance and wellbeing of individuals. One such construct is self-esteem (Rosenberg, 1965, 2016), which is assumed to be efficacious in understanding individual differences in performance. The scientific study of self-esteem has its origin in the work of William James, who conceptualized it as a set of positive feelings about oneself and the amount of actual work (Hewitt, 2005; Seligman, Reivich, Jaycox, \& Gillham, 1996). Self-esteem has also been conceptualized as a set of favourable or unfavourable self-attitude (Rosenberg, 1965) and a sense of worth (Blascovich \& Tomaka, 1991). Selfesteem is rooted in trust, unconditional love and security of childhood that progress with the positive and negative evaluations (Coopersmith, 1967; Seligman et al., 1996). According to self-determination theory, all individuals possess an inborn capacity of intrinsic motivation that directs people to explore, absorb and master their environment which is represented through higher self-esteem (Ryan \& Deci, 2004). A high level of self-esteem upholds positive affect and personal growth, life satisfaction and wellbeing as well as helps in coping by acting as a buffer against anxiety (Pyszczynski, Greenberg, Solomon, Arndt, \& Schimel, 2004). Self-esteem also carries survival value for individuals by promoting a securely attached style that, in turn, promotes happiness and well-being (Pyszczynski et al., 2004).

In the recent past, some weaknesses of self-esteem have been identified. For instance, the exogenic nature of self-esteem makes it fragile, fluctuating and relative, which makes it unstable and unpredictable (Ryan \& Deci, 2004). Self-esteem has been suggested to be based on the comparison, performance evaluations and social ideal that make it more affected by external conditions (Neff, Hsieh, \& Dejitterat, 2005). Additionally, overemphasis on self-esteem may lead individuals to distortion and narcissistic tendencies (Damon, 1995; McMillan, Singh, \& Simonetta, 1994; Neff et al., 2005). As an alternative to self-esteem, selfcompassion, a construct derived from Buddhist philosophy, has been identified; it denotes a set of healthy and positive self-attitudes with better life outcomes and lesser chance to be linked with psychopathological tendencies (Neff, 2003a, b). Self-compassion refers to the manner through which an individual relates himself with his self without considering self-worth. It comprises three bipolar dimensions that function in close connection and interdependence with one another (Dreisoerner, Junker, \& van Dick, 2020). Selfkindness denotes being kind to oneself in place of being self-judgmental in the face of hardships whereas common humanity reflects the extent to which one's experience is common to all human beings and a lesser degree of isolation from other people. Lastly, mindfulness represents remaining in awareness of one's own experiences of pain and failures in place of rejecting or denying them or over-identifying with them (Neff, 2003a, b). Many positive life outcomes of practising self-compassion have been identified. For example, self-compassion has been reported to be associated closely with well-being and many health outcomes and has efficacious applications in clinical and health settings (Muris, van den Broek, Otgaar, Oudenhoven, \& Lennartz, 2018; Sirois, 2020; Verma \& Tiwari, 2017). Self-compassion has evinced its protective strengths for psychological well-being and negative links with psychopathological symptoms such as anxiety, depression, stress, and other mental health issues (MacBeth \& Gumley, 2012).

Self-compassion has been suggested to be closely related to personality traits because various personality attributes have close links with individual differences at the affective level and environmental responsivity (Corr, 2008; Revelle, 1995). Studies examining the link of self-compassion with positive psychological health and the Five-Factor Model of personality document a positive link between selfcompassion and a set of qualities and personality traits indicating healthy functioning such as happiness, optimism, positive affect, wisdom, personal initiative, curiosity and exploration, agreeableness, extroversion and conscientiousness (Neff, Kirkpatrick, \& Rude, 2007a; Neff, Rude, \& Kirkpatrick, 2007b). Self-compassion shows a significant negative association with negative affect and neuroticism but a positive correlation with agreeableness as it is associated with kind, connected and emotionally balanced attributes which enhance the ability to get along with others (Neff et al., 2007a, b). Given self-compassionate individuals' disposition to refrain from worrying about their impression and remain emotionally stable (which promotes more responsible behaviours), selfcompassion was found to be linked with both extraversion and conscientiousness (Neff et al., 2007a, b). On the other hand, self-compassion did not show relationships with openness to experiences which involve active imagination, a higher inclination to aesthetics, a strong liking of diversity and non-judgmental attitudes (Costa \& McCrae, 1992). Similar patterns of relationship between the five facets of the Big-five personality model and self-compassion have also been reported among Indians (Thurackal, Corveleyn, \& Dezutter, 2016).

Although the foregoing studies provide ample evidence that self-compassion is linked with personality traits using a very comprehensive and widely studied model of personality, i.e., the Big-Five model, little is known about how self-compassion and its various domains relate with the Vedic model of personality. Given the origin of the construct of self-compassion 
in the classical Indian tradition (Buddhism), it would be interesting to explore its relationship with the personality traits rooted in the Indian tradition, viz., the Vedic model of personality. The Vedic personality theory represents a comprehensive paradigm for the understanding of the human personality in terms of an interdependent set of three (Tri) qualities (Gunas) representing the material, social and psychological dimensions of human functioning with equal relevance to understanding material things (Agrawal, 2020; Das, 1999). Thus, the Vedic model of personality is also referred to as the Triguna theory of personality. According to this model, the three $\mathrm{Gu}$ nas (qualities) represent the three major domains of personality each having a set of several traits (Wolf, 1998). The three qualities or domains of personality in this model are Sattva (characterized by purity and goodness), Rajas (characterized by passion or action tendency) and Tamas (with core features of dullness, darkness or destructiveness).

The core traits defining Sattva Guna include purity, honesty, seriousness, dutifulness, detachment, restrain, mental equilibrium, respect for superiors, satisfaction, intelligence, sense of control and strong determination (Bhaktivedanta, 1994; Dasgupta, 1961). The Sattva Guna has been conceptualized as a set of attributes that make people more positively attached to the worldly life with restraint and remain unaffected in the face of success and failures of life (Dasgupta, 1961). Thus, individuals with a higher Sattvic quality reflect a higher life satisfaction, generosity, ordinariness, self-restraint and goodness (Dasgupta, 1961). On the other hand, the Rajas Guna represents passionate activity, strong gratification desire, lower spiritual interest, a higher dissatisfaction with life achievements, an envious tendency towards others and faith in the materialistic mindset (Agrawal, 2020; Das, 1999). According to Bhagavad Gita, Rajasic people are guided by their false ego and are greedy, envious, impure and pleasure-seeking by nature (Agrawal, 2020; Das, 1999). Lastly, people dominated by the Tamas Guna show psychological imbalance, resentment, lack of knowledge, egotism, sadness, idleness, procrastination and a feeling of helplessness (Das, 1999; Shilpa \& Venkatesha Murthy, 2011). The relative higher presence of Tamas Guna is visible in lower insight, erroneous orientation, carelessness, idleness and excess sleep (Dasgupta, 1961; Shilpa \& Venkatesha Murthy, 2011).

The Triguna or Vedic model of personality thus may be called the Indian Big-Three Model of personality consisting of the three major domains of Sattva, Rajas and Tamas. The Vedic model posits that all the three Gunas (qualities or super-ordinate traits) are present in all human beings in a lesser or greater degree and individual differences in the nature and character (personality) of an individual result from the relative dominance and the interplay of these traits (Agrawal, 2020; Bernard, 1996; Das, 1999; Potter, 1970; Shilpa \& Venkatesha Murthy, 2011).

The relevance of the Triguna theory of personality for understanding the health and well-being of individuals across cultures has been well documented (Singh, Jain, Kaur, Junnarkar, \& Slezackova, 2016). Researchers have noted that the Sattva domain of personality showed a link with such positive life outcomes as mental health, well-being, and positive experiences whereas the Tamas dimension showed negative associations with these measures and the Rajas showed mixed relationships (Khanna, Singh, Singla, \& Verma, 2013; Singh et al., 2016; Singh \& Slezáčková, 2013). The observed pattern of association between Triguna (Sattva, Rajas and Tamas) and life outcomes is quite congruent with the basic attributes of the three domains of the Vedic personality model. For instance, Sattva is characterized by spiritual orientation, positive cognitions and affect, relationship and an inclination to self-growth (Agrawal, 2020; Sharma, Salvi, \& Sharma, 2012; Sitamma, Sridevi, \& Krishna Rao, 1995), and thus its association with such positive outcomes as mental health, wellbeing, and positive emotional experiences (Khanna et al., 2013; Singh et al., 2016; Singh \& Slezáčková, 2013) seems theoretically congruent. Similarly, the Rajas represents sharp perceptions, aggressiveness and decreased life satisfaction (Datar \& Murthy, 2019; Wolf, 1998) whereas the Tamas comprises poor cognition, dysfunctional memory, a delusional tendency and passivity (Sitamma et al., 1995).

Personality is an important predictor of the goal orientation of an individual, and an upsurge in studies linking personality and goal orientation has been noted in recent years. In their meta-analysis of the Big Five personality and goal-setting, expectancy and self-efficacy theories of motivation, Judge and Ilies (2002) reported strong correlations among the basic attributes of the Big Five personality traits and accepted criteria of motivated behaviours. However, the findings of this meta-analysis are limited because it did not include in the analysis goal orientation theory, which is considered important to understand the mental framework relevant for the way people interpret and respond to goal attainment situations during training and task performance (Elliot \& McGregor, 2001). However, subsequent studies reported interrelatedness of various personality traits such as extraversion and neuroticism with goal orientation (Harackiewicz, Barron, Pintrich, Elliot, \& Thrash, 2002).

Self-compassion has also been shown to be closely related to goal orientations, motivational frameworks and achievements of people of all age groups. For example, mastery goals lead individuals towards curiosity, standardize performance and acceptance of their mistakes and intrinsic motivation which entails increased perseverance in tasks, readiness to seek help and enjoyment (Neff et al., 2005). People with per- 
formance goals tend to exhibit apprehension of being outperformed and fear mistakes on one hand and show motivation to enhance their self-worth on the other. Neff et al. (2005) conducted a study on 110 undergraduate students and reported that self-compassion was positively correlated with mastery goals and intrinsic motivation, and negatively with performance goals. Contrarily, another study of 91 students could not replicate these findings (Williams, Stark, \& Foster, 2008). Thus, there is a strong need to conduct further studies to develop an insight into the relationship between personality, self-compassion and achievement goal orientations. Self-compassion is linked with the ways people approach their work (Barnard \& Curry, 2011) and may help enhance academic performance by increasing perceived competence (Neff et al., 2005) and resilient self-appraisals (Barnard \& Curry, 2011; Leary, Tate, Adams, Allen, \& Hancock, 2007).

Although the earlier studies provide some evidence that self-compassion is linked with an individual's goal orientation, most studies used the SelfCompassion Scale (SCS) developed by Neff (2003b), which has recently been questioned for its conceptual framework and operationalization. Inclusion of such domains as self-judgement, isolation and overidentification in a measure of self-compassion has been questioned by researchers as they represent the opposite of the construct of self-compassion, viz., self-contempt or self-rejection (e.g., Muris, Otgaar, $\&$ Petrocchi, 2016; Murris et al., 2018). The differential pattern of relationship of the positive and negative domains of self-compassion with measures of mental health further cast doubt that self-judgement, isolation and over-identification dimensions of the SCS measure self-compassion. For instance, in a metaanalytic review, Muris and Petrocchi (2017) observed that positive components of self-compassion (selfkindness, common humanity and mindfulness) were negatively associated with mental health problems whereas the negative components (self-judgement, isolation and over-identification) exhibited a positive association with psychopathological symptoms. Similar findings have also been reported by other researchers (Lopez, Sanderman, Ranchor, \& Schroevers, 2018; Pandey, Tiwari, Parihar, \& Rai, 2019; Pandey et al., 2020; Pfattheicher, Geiger, Hartung, Weiss, \& Schindler, 2017). These observations suggest that the six domains of the SCS seem to measure two related yet different domains, viz., self-compassion and self-rejection or self-contempt. The present study prefers to use the labels positive self-compassion and negative self-compassion for the said two broader domains of the SCS in order to maintain continuity with the original measure.

The picture is further complicated by the factor analytic studies which extend the hypothesis that self-compassion is best represented by three bipolar dimensions (Cleare, Gumley, Cleare, \& O'Connor,
2018; Neff, Whittaker, \& Karl, 2017). Although these observations point towards the possibility that the SCS consists of both positive and negative aspects of self-compassion, it does not provide support for the two-factor model of self-compassion i.e., positive and negative self-compassion. Researchers have argued that self-judgment, isolation and over-identification exhibit clear similarities with ruthless self-criticism (Zuroff, Igreja, \& Mongrain, 1990), social withdrawal and loneliness (Rubin \& Coplan, 2004), and selfabsorption and self-focused rumination (Lyubomirsky \& Nolen-Hoeksema, 1995). Thus, the domains of self-judgement, isolation and over-identification can be better summarized by the latent factor of negative self-compassion. Recently, Muris et al. (2018) presented some evidence for the validity of the two factor (or bi-factor) model of positive and negative self-compassion. These researchers observed that positive self-compassion was linked with adaptive coping, planning, positive reframing, self-forgiveness and flourishing and healthy functioning while negative self-compassion was related to maladaptive coping, anxiety and depression (Muris et al., 2018; Muris \& Otgaar, 2020; Pandey et al., 2019, 2020; Sirois, Molnar, \& Hirsch, 2015). Similar findings were also reported by some other researchers who have found a positive correlation between positive self-compassion and various adaptive coping styles such as active tackling, social support seeking, and reassuring thoughts but a negative association with negative self-compassion (Allen \& Leary, 2010; Rai \& Tiwari, 2019; Tiwari et al., 2020).

\section{CURRENT STUDY}

It is evident from the preceding review that the construct of self-compassion as assessed by the Self-Compassion Scale (SCS) may be measuring two linked yet polar opposite constructs, viz. positive and negative self-compassion puts a caveat on the earlier findings linking self-compassion with goal orientations. This raises a need to further examine the link of the two factors of self-compassion with goal orientations. Further, it is also evident that the existence of the constructs of positive and negative self-compassion is based on indirect empirical evidence and not a direct empirical test of the said two-factor structure solution. The present study aims to address such gaps by assessing the validity of the mentioned two-factor solution of the SCS (using both exploratory and confirmatory factor analytic approaches) and the role of positive and negative self-compassion in understanding the goal orientations of Indian students.

The preceding empirical evidence also documents self-compassion as a relevant psychological construct that may help to better understand the performance and functioning of individuals (including goal orien- 
tations) in association with personality. Researchers have argued that future studies should focus on the way self-compassion is related to goal orientations in terms of relevant personality traits (Alhadabi \& Karpinski, 2020; Babenko, Mosewich, Abraham, \& Lai, 2018). Although a few studies have examined the linkages between self-compassion, personality traits and goal orientations, to the best of our knowledge the interplay of the Indian personality construct of Triguna (characterized by three qualities/dimensions, viz. Sattva, Rajas and Tamas), self-compassion and academic goal orientations has not been studied yet. This is considered important since both the constructs of Triguna and self-compassion have their roots in the Indian tradition; thus, exploring their link and interplay in explaining the goal orientations of the Indian students would bring new insights into the underlying psychological mechanisms.

To sum up, in view of the gaps inherent in the current literature mentioned above, the present study aims to examine the validity of the new conceptualization of the two-factor model of the existing SelfCompassion Scale (Neff, 2003b), and to understand the role of the Triguna theory of personality and the two-factor model of self-compassion in shaping the goal orientations of the Indian students. Towards this end, we first examined the intercorrelations among the three domains of personality, two factors of selfcompassion and three aspects of academic goal orientations followed by explicating the relative importance of personality and self-compassion in shaping the academic goal orientations of the Indian students. We also explored the interplay of the three domains of the Vedic personality model (Sattva, Rajas, and Tamas) and two factors of self-compassion, using a structural equation modelling approach, to develop better insight into the mechanisms underlying the academic goal orientations (mastery, performance-approach and performance-avoidance) of the Indian students. It is speculated that the Vedic personality traits will shape an individual's tendency to be self-compassionate (disposition for positive self-compassion) or selfrejecting (disposition for negative self-compassion), which in turn will shape his/her goal orientations. However, the three Gunas are also likely to have a direct effect on the academic goal orientations.

\section{PARTICIPANTS AND PROCEDURE}

\section{PARTICIPANTS}

A correlational research design was employed which used a convenience sampling method to choose the participants for the study. Data were collected from 500 students enrolled in different undergraduate and postgraduate programmes of Doctor Harisingh Gour University, Sagar, Madhya Pradesh, India. After screening for outliers, 377 participants aged 17 years to 25 years $(M=20.01, S D=2.02)$ were left. Out of these 377 participants, 190 were males with the age ranging from 17 years to 25 years $(M=20.13, S D=2.21)$ and the other 187 were females with age spanning from 18 years to 25 years $(M=19.88, S D=1.81)$. The outliers were screened as per the guidelines suggested by Donald (2016). The two groups did not differ significantly in their mean age scores $(t(375)=1.17$, $p=.242$ ). The majority of the participants belonged to the Hindu religion $(82.40 \%)$ and the rest were Jains $(13.80 \%)$ and Muslims (3.80\%). Also, the majority of them were from rural or suburban areas $(64.40 \%)$ and the rest $(35.60 \%)$ reported their domicile from urban areas. The participants who were pursuing their graduate or postgraduate programmes, were aged between 17 years and 25 years and exhibited apparently normal physical and mental health (as reported by them) were included in the study. Those who were attending lower or higher academic programmes, were younger or older and facing some sort of reported health problems were excluded.

\section{PSYCHOMETRIC TOOLS}

The scales employed in the present study were first translated from English to Hindi followed by a backtranslation from Hindi to English by three experts according to the suggestions of the leading researchers (Behr, 2017; Brislin, 1970). Additionally, their face validity was established by these researchers keeping in mind the basic constructs before the final decision to use these tools. These researchers also went through the various constructs and validated each item of the scales. The following psychometric tools were employed to collect the data:

The Vedic Personality Inventory. The Sattva, Rajas and Tamas Gunas (qualities) of personality were measured with the help of the Vedic Personality Inventory developed by Wolf (1998). This personality scale represents a reliable measure of Triguna personality traits and has also been well validated along with the relevant criterion (Wolf, 1998). The measure of personality comprises 56 items with a seven-point scale that ranges from very strongly disagree, strongly disagree, somewhat disagree, neutral, somewhat agree, strongly agree to very strongly agree. Out of 56 items, 15 items were standardized to measure Sattva Guna and the other 19 items and 22 items were developed for Rajas and Tamas Gunas, respectively. This personality questionnaire has good internal consistency ( $\alpha=.70$ to .92) measured in terms of Cronbach's $\alpha$ (Wolf, 1998). Other researchers have reported reliability coefficients of this measure that ranged from .74 to .79 (Das, 1999; Shilpa \& Venkatesha Murthy, 2012). The scale also possesses a good construct validity across cultures (Singh et al., 2016). 
Self-Compassion Scale. The self-compassion of the participants was assessed through the SelfCompassion Scale developed by Neff (2003b). This measure of self-compassion denotes thoughts, emotions and behaviours related to all the dimensions of self-compassion proposed by Neff (2003b). The scale comprises statements that assess the extent to which people respond to their feelings of inadequacy with self-kindness, self-judgment, common humanity, isolation, mindfulness and over-identification. The scale consists of 26 items with a five-point scale from almost never to almost always. Out of a total of 26 items, 5 items belonged to self-kindness, 5 items to self-judgment, 4 items to common humanity, 4 items to isolation, 4 items to mindfulness and 4 items to over-identification. The cumulative scores on selfkindness, common humanity and mindfulness subscales were indicative of positive self-compassion whereas the sum of the scores on self-judgment, isolation and over-identification represented negative self-compassion. The internal reliability of the Self-Compassion Scale has been reported to be consistently good in many studies across cultures (Allen, Goldwasser, \& Leary, 2012; Neff \& Pommier, 2013; Werner et al., 2012). A large number of studies have shown the empirical validity of the six-factor structure of the translated versions of the scale across cultures (Arimitsu, 2014; Azizi, Mohammadkhani, Foroughi, Lotfi, \& Bahramkhani, 2013; Castilho, Pinto-Gouveia, \& Duarte, 2015; Garcia-Campayo et al., 2014; Montero-Marin et al., 2018) and populations (Neff et al., 2020; Tóth-Király \& Neff, 2020).

Achievement Goal Orientations Scale. The achievement goal orientations of the participants were measured with the help of Achievement Goal Orientation Scale (Midgley et al., 1998). The scale comprises 18 items with a 5-point scale that ranges from almost never to almost always. This measure contains three subscales of achievement goal orientations, namely, task goal orientation, ability-approach and abilityavoidance goal orientations. These three subscales denote mastery goals, performance-approach goals and performance-avoidance goals, respectively. The first subscale consists of six items that represent the concern with the understanding and learning of the class materials while the second subscale contains six items that measure the concerns of the participants who were trying to outperform others to demonstrate their ability. The last subscale also contains six items that reflect the concern of the participants with not seeing themselves as incompetent or inferior to others. This measure of achievement goal orientations has exhibited good psychometric properties (Midgley et al., 1998). The researchers have estimated internal reliability for mastery, performanceapproach and performance-avoidance to be $\alpha=.81$, $\alpha=.81$, and $\alpha=.86$, respectively (Midgley et al., 1998; Neff et al., 2005).

\section{PROCEDURE}

The proposal of the study was submitted to the Ethics Committee of Doctor Harisingh Gour University, Sagar, Madhya Pradesh, India. After the approval, the participants were consulted personally and debriefed about the basic goals of the study. The data collection was started only after the submission of written consent by the participants. The scales were administered in small groups of 20 to 25 participants for the sake of convenience and accuracy. To ascertain the accuracy of the understanding of the instructions and reliability of the responses of the participants, the first author read out the instructions loud along with the speed of the participants to control the time of presentation of each item of the measures of the study. No compensation was provided to them for their participation in the study. After completion of the data collection, the raw scores of the scales were computed.

\section{PLAN OF DATA ANALYSIS}

The obtained raw data were arranged with care as per the design of the statistical analysis. The data of the study were treated with the help of SPSS Statistics version 26. Determination of the mean, standard deviations, factor analysis, coefficient of correlation, hierarchical regression analysis and path analysis were carried out. As the data were not normally distributed, the bootstrapping method of computing correlations and hierarchical regression were employed adopting the criteria of 5000 bootstrap samples.

\section{RESULTS}

The results have been presented in four sections. In the first section, the results of factor analysis have been displayed followed by the second section which comprises the coefficients of correlations. The hierarchical regression analysis has been presented in the third section. The fourth section entails the results of path analysis.

\section{FACTOR ANALYSIS}

As conceptualized in the present study and indirectly supported and validated by earlier studies, the twofactor model of self-compassion was validated using both exploratory and confirmatory factor analytic approaches. In the exploratory factor analytic approach, we conducted a principal component analysis on the six-subscales of the SCS. The Kaiser-MeyerOlkin measure of sample adequacy was well over .5 (.68) and the Bartlett test of sphericity was also found 
to be significant, suggesting that the correlation matrix is adequate for factor analysis. All the diagonal values of the anti-image correlation matrix were also above .50 , providing further evidence for the suitability of the data for factor analysis. The scree plot suggested retaining two components, and thus two components were extracted and rotated using the Varimax method. The rotated component matrix is presented in Table 1.

It is evident from the rotated component matrix that mindfulness, self-kindness and common humanity loaded significantly on the first component (or factor) and may be labelled as positive self-compassion. Isolation, over-identification and self-judgement loaded significantly on the second component and this component may be labelled as negative self-compassion. Thus, the findings of the exploratory factor analysis clearly provide support to our hypothesis that the SCS is better represented by a two-facto model, viz., positive self-compassion and negative self-compassion. The first factor (positive self-compassion) explained $32.44 \%$ of the total variance whereas the second factor (negative self-compassion) explained an additional $32.22 \%$ of the total variance.

To further validate the said two-factor model of self-compassion, a maximum likelihood confirmatory factor analysis was conducted and after allowing a few error terms to covary the said two factor model (see Figure 1) was found to have a good fit to the data $\left(\chi^{2} / d f=2.45\right.$, GFI $=.992$, AGFI $=.967$, $\mathrm{TLI}=.964, \mathrm{CFI}=.988$, RMSEA $=.054$, SRMR $=.032$ ) The standardized factor loadings are displayed in Figure 1 , and it is evident that all the factor loadings were above .60 . These observations provide further evidence for the validity of the two-factor model of the Self-Compassion Scale. Further, the correlation between the two factors (i.e. positive and negative self-compassion) was also found to be negative but low $(r=-.26)$, suggesting that it is better to treat positive and negative self-compassion as independent yet minimally negatively related.

\section{CORRELATION ANALYSIS}

The mean, standard deviation and coefficient of correlations among the overall scores of the predictors and criterion measures were computed (see Table 2). Sig-

Table 1

Rotated two-factor model of the Self-Compassion Scale (Neff, 2003b)

\begin{tabular}{lcc}
\hline \multirow{2}{*}{$\begin{array}{l}\text { Dimensions } \\
\text { of self-compassion }\end{array}$} & \multicolumn{2}{c}{ Components } \\
\cline { 2 - 3 } Mindfulness & .823 & 2 \\
Self-kindness & .796 & \\
Common humanity & .763 & \\
Isolation & & .828 \\
Over-identification & & .825 \\
Self-judgement & & .727 \\
\hline
\end{tabular}

Note. $N=377$. The extraction method was principal component factoring with a Varimax method rotation. Adapted from Neff, 2003 b.

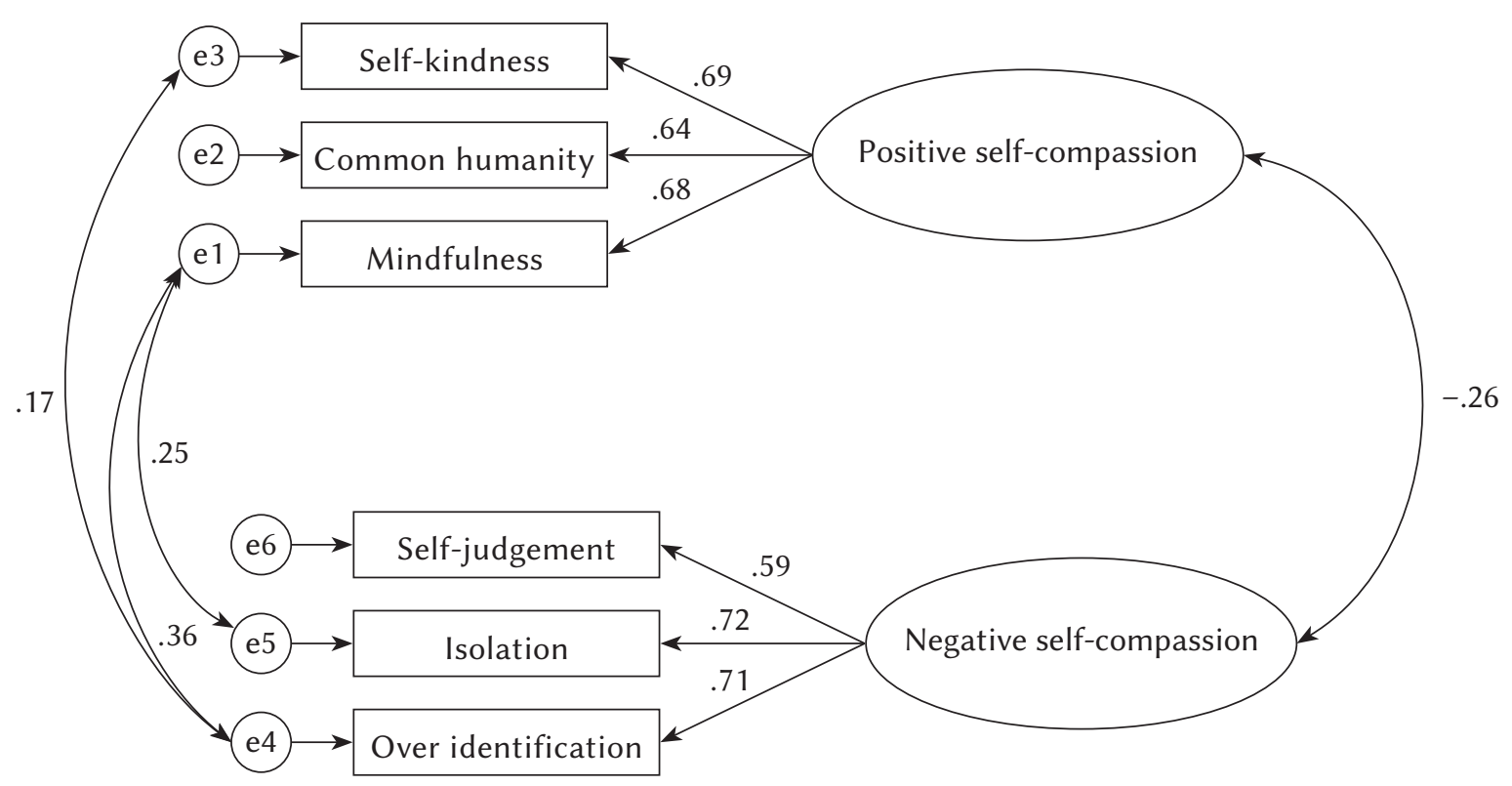

Figure 1. Correlated two-factor model of the Self-Compassion Scale (Neff, 2003b). 
Table 2

Zero-order correlations among various dimensions of personality, self-compassion and academic goal orientations of the participants $(N=377)$

\begin{tabular}{|c|c|c|c|c|c|c|c|c|c|c|c|}
\hline S. No. & Measures & $M(S D)$ & 1 & 2 & 3 & 4 & 5 & 6 & 7 & 8 & 9 \\
\hline 1. & Age & $\begin{array}{l}20.01 \\
(2.02)\end{array}$ & 1 & & & & & & & & \\
\hline 2. & Sattva & $\begin{array}{l}80.64 \\
(9.34)\end{array}$ & .04 & 1 & & & & & & & \\
\hline 3. & Rajas & $\begin{array}{c}64.15 \\
(12.42)\end{array}$ & .03 & $-.17^{* *}$ & 1 & & & & & & \\
\hline 4. & Tamas & $\begin{array}{c}71.26 \\
(17.23)\end{array}$ & -.03 & $-.29^{* *}$ & $.58^{* *}$ & 1 & & & & & \\
\hline 5. & PSC & $\begin{array}{l}48.45 \\
(6.50)\end{array}$ & -.01 & $.30^{* *}$ & -.10 & $-.13^{*}$ & 1 & & & & \\
\hline 6. & NSC & $\begin{array}{l}38.82 \\
(8.11)\end{array}$ & .04 & .05 & $-.26^{* *}$ & $-.44^{* *}$ & -.10 & 1 & & & \\
\hline 7. & MAS & $\begin{array}{l}24.92 \\
(2.71)\end{array}$ & .03 & $.28^{* *}$ & $-.16^{* *}$ & $-.11^{*}$ & $.29^{* *}$ & -.004 & 1 & & \\
\hline 8. & PAPP & $\begin{array}{l}23.19 \\
(3.91)\end{array}$ & -.04 & $.16^{* *}$ & $.12^{*}$ & .06 & $.14^{* *}$ & $-.19^{* *}$ & $.21^{* *}$ & 1 & \\
\hline 9. & PAVO & $\begin{array}{l}18.17 \\
(4.87)\end{array}$ & .06 & .09 & $.11^{*}$ & .09 & $.19^{* *}$ & $-.25^{* *}$ & $.10^{*}$ & $.39^{* *}$ & 1 \\
\hline
\end{tabular}

Note. PSC - positive self-compassion, NSC - negative self-compassion, Sattva - Sattva Guna (quality), Rajas - Rajas Guna (quality), Tamas - Tamas Guna (quality), MAS - mastery, PAPP - performance-approach, PAVO - performance-avoidance; ${ }^{*} p<.05,{ }^{* *} p<.01$.

nificant positive correlations were observed among Sattva Guna (quality) and positive self-compassion, mastery and performance-approach and performance-avoidance while it had negative correlations with Rajas and Tamas Gunas (see Table 2). The Rajas Guna showed significant positive correlations with the Tamas Guna, performance-approach and performance-avoidance and negative correlations with negative self-compassion and mastery. The Tamas Guna showed negative correlations with positive self-compassion, negative self-compassion and mastery along with small positive non-significant correlations with performance-approach and performance-avoidance (see Table 2). Moreover, positive self-compassion was positively correlated with mastery, performance-approach and performance-avoidance along with a small non-significant negative correlation with negative self-compassion. Negative self-compassion exhibited significant negative correlations with performanceapproach and performance-avoidance, and a small negative correlation with mastery (see Table 2).

\section{HIERARCHICAL REGRESSION ANALYSES}

Hierarchical regression was employed to partial out the relative contributions of gender, age, personality
(Sattva, Rajas and Tamas Gunas) and self-compassion (positive and negative aspects) in the variability of the scores of academic goal orientations (mastery, performance-approach and performance-avoidance) of the participants. The demographic variables (gender and age) were entered at step 1 followed by personality (Sattva, Rajas and Tamas Gunas), which was entered at step 2 in a stepwise fashion. Lastly, selfcompassion (positive and negative aspects) was entered at step 3 . The results showed that demographic variables (gender and age) accounted for significant variance by contributing $3.90 \%$ in the scores of mastery $\left(R^{2}=.04, F(2,374)=7.58, p=.001\right)$. Personality also accounted for significant variance in the scores of mastery. Out of three dimensions, the contribution of only Sattva was statistically significant $(10.70 \%)$, which is depicted in Model $2\left(R^{2}=.11, F(3,371)=9.43\right.$, $p=.001)$. In addition to gender and Sattva Guna, positive self-compassion contributed significant variance of $15.50 \%$ to mastery $\left(R^{2}=.16, F(2,369)=10.49\right.$, $p=.001)$. Thus, positive self-compassion $(\beta=.23)$ emerged as the most significant predictor of mastery followed by Sattva Guna $(\beta=.18)$ and gender $(\beta=.14)$ (see Table 3).

The results further showed that demographic variables (gender and age) accounted for significant variance by contributing $2.20 \%$ in the scores of perfor- 
mance-approach $\left(R^{2}=.02, F(2,374)=3.75, p=.024\right)$. Likewise, personality accounted for significant variance in the scores of performance-approach. Out of three dimensions, the Sattva and Rajas Gunas contributed significantly to the performance-approach $(7.30 \%)$, which is presented in Model $2\left(R^{2}=.07\right.$, $F(3,371)=7.15, p=.001)$. In addition to gender and Sattva Guna, negative self-compassion signifi- cantly contributed $10.70 \%$ to performance-approach $\left(R^{2}=.11, F(2,369)=6.99, p=.001\right)$. Thus, Rajas Guna $(\beta=-.19)$ emerged as the most significant predictor of performance-approach followed by negative selfcompassion $(\beta=-.17)$, gender $(\beta=.14)$ and Sattva Guna $(\beta=.13)$ (see Table 4$)$.

Moreover, personality accounted for significant variance in the scores of performance-avoidance

Table 3

Summary of hierarchical regression analysis for variables predicting mastery of the participants $(N=377)$

\begin{tabular}{|c|c|c|c|c|c|c|c|c|c|}
\hline \multirow[t]{2}{*}{ Variable } & \multicolumn{3}{|c|}{ Model 1} & \multicolumn{3}{|c|}{ Model 2} & \multicolumn{3}{|c|}{ Model 3} \\
\hline & B & $S E \mathrm{~B}$ & $\beta$ & B & $S E \mathrm{~B}$ & $\beta$ & B & $S E \mathrm{~B}$ & $\beta$ \\
\hline Gender & 1.06 & .28 & $.20^{* *}$ & .71 & .28 & $.13^{* *}$ & .78 & .27 & $.14^{* *}$ \\
\hline Age & 0.05 & .07 & .04 & .04 & .07 & .03 & .05 & .07 & .04 \\
\hline Sattva & & & & .07 & .02 & $.25^{* *}$ & .05 & .02 & $.18^{* *}$ \\
\hline Rajas & & & & -.02 & .01 & -.11 & -.02 & .01 & -.10 \\
\hline Tamas & & & & .01 & .01 & .04 & .01 & .01 & .05 \\
\hline PSC & & & & & & & .10 & .02 & $.23^{* *}$ \\
\hline NSC & & & & & & & .00 & .02 & .00 \\
\hline$R^{2}$ & & .04 & & & .11 & & & .16 & \\
\hline$\Delta R^{2}$ & & .04 & & & .07 & & & .05 & \\
\hline$\Delta F$ & & $7.58^{* *}$ & & & $9.43^{* *}$ & & & $10.49^{* *}$ & \\
\hline
\end{tabular}

Note. All standardized regression coefficients $(\beta)$ belong to the final step of the analyses; $d f$ Model $1=(2,374)$, Model $2=(3,371)$ and Model 3 = (2, 369); PSC - positive self-compassion, NSC - negative self-compassion, Sattva - Sattva Guna (quality), Rajas Rajas Guna (quality), Tamas - Tamas Guna (quality); ${ }^{* *} p<.01$.

Table 4

Summary of hierarchical regression analysis for variables predicting performance-approach of the participants $(N=377)$

\begin{tabular}{|c|c|c|c|c|c|c|c|c|c|}
\hline \multirow[t]{2}{*}{ Variable } & \multicolumn{3}{|c|}{ Model 1} & \multicolumn{3}{|c|}{ Model 2} & \multicolumn{3}{|c|}{ Model 3} \\
\hline & B & $S E \mathrm{~B}$ & $\beta$ & B & $S E \mathrm{~B}$ & $\beta$ & B & $S E \mathrm{~B}$ & $\beta$ \\
\hline Gender & 1.04 & .40 & $.13^{* *}$ & 1.21 & .41 & .16 & 1.22 & .40 & $.16^{* *}$ \\
\hline Age & -0.07 & .10 & -.04 & -0.09 & .10 & -.05 & -0.08 & .10 & -.04 \\
\hline Sattva & & & & 0.07 & .02 & $.17^{* *}$ & 0.05 & .02 & $.13^{* *}$ \\
\hline Rajas & & & & 0.06 & .02 & $.18^{* *}$ & 0.06 & .02 & $.19^{* *}$ \\
\hline Tamas & & & & 0.00 & .01 & .02 & -0.01 & .02 & -.06 \\
\hline PSC & & & & & & & 0.05 & .03 & .09 \\
\hline NSC & & & & & & & -0.08 & .03 & $-.17^{* *}$ \\
\hline$R^{2}$ & & .02 & & & .07 & & & .11 & \\
\hline$\Delta R^{2}$ & & .02 & & & .05 & & & .03 & \\
\hline$\Delta F$ & & $3.75^{*}$ & & & $7.15^{* *}$ & & & 6.99 ** & \\
\hline
\end{tabular}

Note. All standardized regression coefficients $(\beta)$ belong to the final step of the analyses; $d f$ Model $1=(2,374)$, Model $2=(3,371)$ and Model 3 = (2, 369); PSC - positive self-compassion, NSC - negative self-compassion, Sattva - Sattva Guna (quality), Rajas Rajas Guna (quality), Tamas - Tamas Guna (quality); ${ }^{*} p<.05,{ }^{* *} p<.01$. 
Triguna personality, self-compassion and goal orientations

Table 5

Summary of hierarchical regression analysis for variables predicting performance-avoidance of the participants $(N=377)$

\begin{tabular}{|c|c|c|c|c|c|c|c|c|c|}
\hline \multirow[t]{2}{*}{ Variable } & \multicolumn{3}{|c|}{ Model 1} & \multicolumn{3}{|c|}{ Model 2} & \multicolumn{3}{|c|}{ Model 3} \\
\hline & B & $S E \mathrm{~B}$ & $\beta$ & B & $S E \mathrm{~B}$ & $\beta$ & B & $S E \mathrm{~B}$ & $\beta$ \\
\hline Gender & .67 & .50 & .07 & .82 & .52 & .08 & .86 & .50 & .09 \\
\hline Age & .15 & .12 & .06 & .14 & .12 & .06 & .16 & .12 & .07 \\
\hline Sattva & & & & .06 & .03 & $.12^{* *}$ & .03 & .03 & .05 \\
\hline Rajas & & & & .04 & .03 & .10 & .04 & .02 & .10 \\
\hline Tamas & & & & .02 & .02 & .08 & -.01 & .02 & -.02 \\
\hline PSC & & & & & & & .12 & .04 & $.16^{* *}$ \\
\hline NSC & & & & & & & -.13 & .03 & $-.22^{* *}$ \\
\hline$R^{2}$ & & .01 & & & .04 & & & .11 & \\
\hline$\Delta R^{2}$ & & .01 & & & .03 & & & .07 & \\
\hline$\Delta F$ & & 1.51 & & & $3.70^{*}$ & & & $14.60^{* *}$ & \\
\hline
\end{tabular}

Note. All standardized regression coefficients $(\beta)$ belong to the final step of the analyses; $d f$ Model $1=(2,374)$, Model $2=(3,371)$ and Model $3=(2,369)$; PSC - positive self-compassion, NSC - negative self-compassion, Sattva - Sattva Guna (quality), Rajas Rajas Guna (quality), Tamas - Tamas Guna (quality); ${ }^{*} p<.05,{ }^{* *} p<.01$.

$\left(R^{2}=.04, F(3,371)=3.70, p=.012\right)$. Out of three dimensions, only Sattva Guna contributed $3.70 \%$ significantly to the performance-avoidance of the participants. Model 3 showed that self-compassion also contributed $10.70 \%$ to the performance-avoidance of the participants $\left(R^{2}=.11, F(2,369)=14.60, p=.001\right)$. Thus, negative self-compassion $(\beta=-.22)$ emerged as the most significant predictor of performance-avoidance followed by positive self-compassion $(\beta=.16)$ (see Table 5).

\section{STRUCTURAL RELATIONSHIP MODELLING (PATH ANALYSIS)}

The foregoing findings suggest that the three domains of the Triguna personality theory and selfcompassion are interrelated with each other and they are also linked with the goal orientations of the students. However, the interplay of these two constructs cannot be assessed using the correlation and regression approach and therefore a structural equation modelling approach (especially the path analytic approach) was followed. Using this approach, the structural relationship among the domains of personality, self-compassion and academic goal orientations was modelled and tested. In this path analysis model, the Sattva, Rajas and Tamas domains of the Triguna personality theory were considered as the exogenous predictors whereas positive and negative self-compassion were considered as the endogenous mediator variables between the relationship of the three Gunas with the goal orientations. Based on the factor structure model obtained in the present study (Figure 1), the scores of the latent construct of positive and negative self-compassion were imputed and were used in the model. Thus, it is not the aggregate or total scores of the individual indicators of the constructs of positive or negative self-compassion, but rather it represents the score of the latent constructs based on their respective indicators. The final model representing the interplay of the said variables in understanding the goal orientations of the students is presented in Figure 2. The path standardized coefficients are shown on each path and only those paths that were found statistically significant $(p<.05)$ have been retained in the model. This model was found to be an excellent fit to the data as per the contemporary criteria of goodness of fit $\left(\chi^{2} / d f=1.48\right.$, GFI $=.993$, AGFI $=.974$, TLI $=.986, \mathrm{CFI}=.995, \mathrm{RMSEA}=.031$, SRMR = .027).

From Figure 2, it is evident that the Sattva Guna has a significant direct effect on positive self-compassion $(\beta=.36, p=.001)$, which, in turn, has a significant direct effect on mastery $(\beta=.38, p=.001)$, and performance-approach $(\beta=.21, p=.001)$. However, the Sattva was found to have an indirect effect on performance-avoidance $(\beta=.07, p=.001)$, performance-approach $(\beta=.05, p=.003)$, as well as mastery $(\beta=.09$, $p=.005)$ through positive self-compassion. On the other hand, the Rajas Guna did not show significant direct effects on either positive or negative self-compassion $(p>.05)$ but it showed a significant direct effect on performance-approach $(\beta=.13, p=.001)$ and 


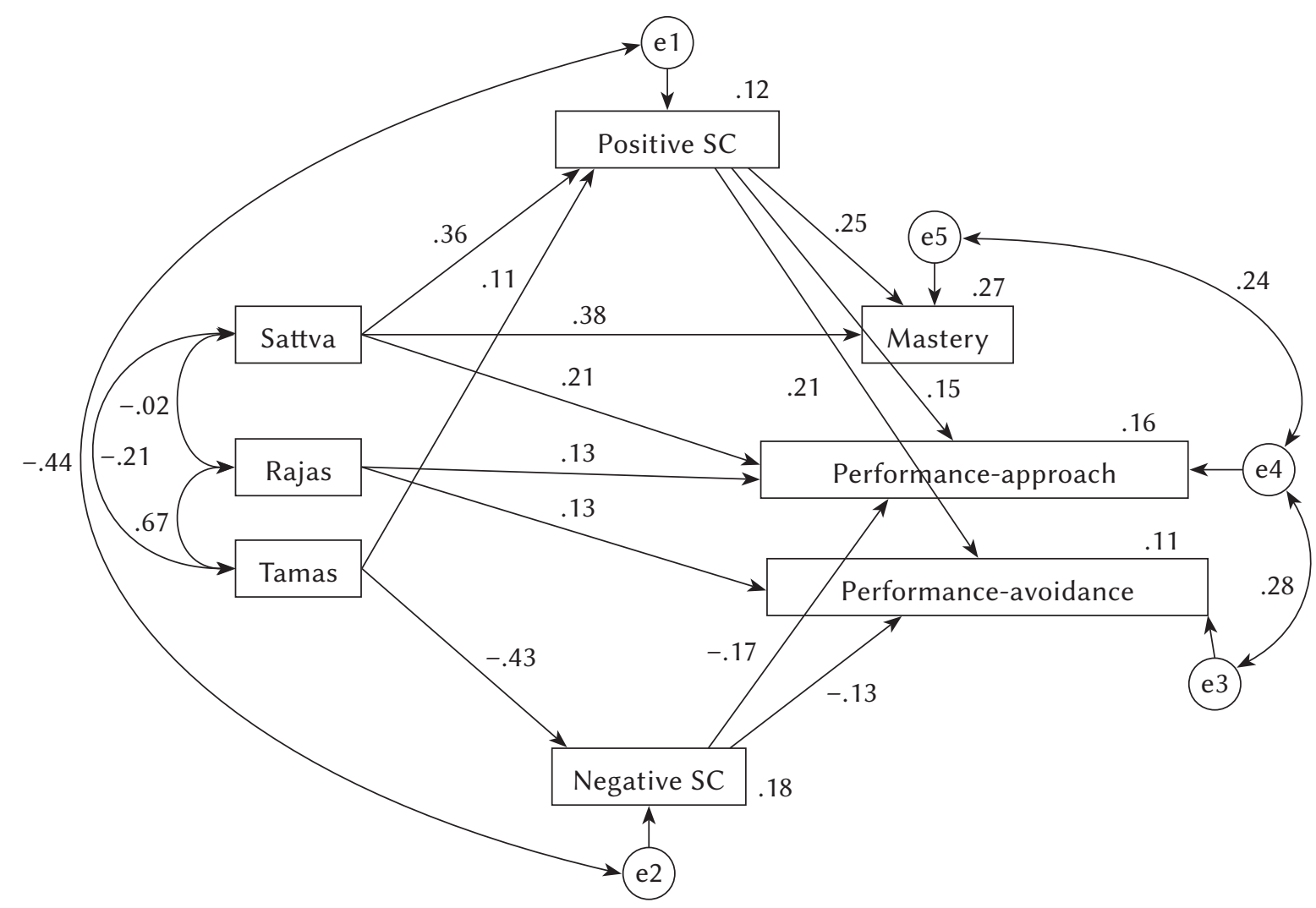

Figure 2. The interplay of the three Gunas (Sattva, Rajas, \& Tamas) and positive-negative self-compassion in predicting the goal orientations.

performance-avoidance $(\beta=.13, p=.011)$. Further, the Tamas Guna showed a significant direct effect on positive self-compassion $(\beta=.11, p=.013)$ as well as negative self-compassion $(\beta=-.43, p=.001)$. Further, the Tamas was found to have a significant indirect effect on performance-avoidance both through negative self-compassion $(\beta=.06, p=.010)$ and positive self-compassion $(\beta=.02, p=.005)$. Similarly, its significant indirect effect was observed on performanceapproach both through negative self-compassion $(\beta=.08, p=.001)$ and positive self-compassion $(\beta=.02$, $p=.008)$. However, the indirect effect of Tamas on mastery was mediated only by positive self-compas$\operatorname{sion}(\beta=.03, p=.009)$.

\section{DISCUSSION}

The findings of the present study proved the contention that Triguna personality and self-compassion have a significant role in shaping the academic goal orientations of the participants. The factor analysis showed the empirical existence of the two-factor structure of the existing Self-Compassion Scale of Neff (2003b). The three dimensions of Triguna personality model evinced dissimilar relevance to explicate the two dimensions of self-compassion and dif- ferent academic goal orientations. Likewise, positive and negative self-compassion exhibited significantly dissimilar roles in shaping the academic goal orientations. Gender, personality and self-compassion accounted for significant variance in the scores of the three academic goal orientations.

The Triguna personality theory has been suggested to be empirically useful to understand individual and intra-individual differences in cognitive, affective and behavioural dimensions (Ilavarasu, Mohan, \& Hankey, 2013). A relative abundance of the Sattva Guna cultivates fearlessness, purity of heart, truthfulness, calmness, peacefulness and compassion towards other beings while the dominance of Rajas Guna is linked with higher passion, anxiety, industriousness, sensuousness, jealousy and a lower spiritual persuasion. Tamas Guna catalyses ignorance, laziness, delusiveness, destructive behaviours, drowsiness, aggression, fear and idleness (Betal, 2015; Krishnamurthy, 1999). The basic attributes of the Sattva Guna make a person happy, compassionate, creative, satisfied and positive (Khanna et al., 2013; Krishnamurthy, 1999). Trigunas represent an array of behavioural predispositions which make it possible to develop a proper connection with one's self according to the changing demand of the situations (Krishnamurthy, 
1999). Thus, the dissimilar nature and extent of correlations and predictive strengths of Trigunas for the positive and negative self-compassion in the present study are supported by these findings.

The relationship between Triguna personality traits and academic goal orientations can be explained in terms of the basic qualities of Sattva, Rajas and Tamas Gunas. Researchers have argued that Sattva Guna pertains to the qualities of purity, honesty, seriousness, dutifulness, detachment, restrain, mental equilibrium, respect for superiors, satisfaction, intelligence, sense of control and strong determination (Bernard, 1996; Bhaktivedanta, 1994; Dasgupta, 1961; Shilpa \& Venkatesha Murthy, 2011). Moreover, the Sattvic quality has been argued to reflect lowered worldly attachments and to remaining in balance in the odds of life and many positive personality attributes such as higher life satisfaction, ordinariness, simple lifestyle, seriousness, self-restraint attitude and goodness (Dasgupta, 1961; Potter, 1970; Shilpa \& Venkatesha Murthy, 2011). Sattva Guna represents fearlessness, purity of heart, control over senses, truthfulness, absence of anger, renunciation, peacefulness, compassion and absence of indecisiveness (Krishnamurthy, 1999). Sattva Guna also carries emotional stability (Betal, 2015), positive attitude, happiness, lightness, consciousness and spiritual orientation (Planet Ayurveda, 2020), abstract memory, realistic perception, and productive and abstract thinking (Dhulla, 2011). These attributes of Sattvic quality may be behind its positive correlation and predictive strength for mastery of the participants.

The Rajas Guna denotes passionate activity, strong gratification desire, lower spiritual interest, a higher dissatisfaction with the achievements of life, envious tendency and faith in a materialistic mindset (Das, 1999; Potter, 1970; Shilpa \& Venkatesha Murthy, 2011). Rajas Guna cultivates rage, ferocious desires, restlessness, discontent, strong need to satisfy desires, constructive orientation, courage and enthusiasm, sensuousness, hatred, jealousy, lower spiritual pursuit, imitation, passion, anxiety, industriousness and higher ambition. It is also characterized by constructive but dominating nature and restlessness (Betal, 2015), active, stimulation-seeking, and achievementorientation (Planet Ayurveda, 2020), and concrete memory, ego-involved perceptions, scattered thinking and imagination (Dhulla, 2011). These qualities of Rajas may be acting behind its significant contributions in the variability of performance-approach.

Conversely, the Tamas Guna is characterized by psychological imbalance, resentment, greed, lack of knowledge, egotism, sadness, idleness, procrastination and a feeling of helplessness (Das, 1999; Shilpa \& Venkatesha Murthy, 2011) and people higher in this quality exhibit lower insight, erroneous orientation, carelessness, idleness and excess sleep (Dasgupta, 1961; Shilpa \& Venkatesha Murthy, 2011).
Tamas Guna shows ignorance, lethargy, delusion, destruction, tiredness, anger and fear (Krishnamurthy, 1999). Additionally, it represents indifference (Betal, 2015), malpractices and self-centeredness (Banerjee, Pathak, \& Mathur, 2020), resistance, heaviness, negative thoughts, inertness, lethargy and apathy (Planet Ayurveda, 2020), and distorted perception and confused thinking (Dhulla, 2011). These might be the reasons behind its negative correlations with positive self-compassion and mastery as well as its small positive non-significant correlations with performanceapproach and performance-avoidance.

It has been suggested that the Sattva Guna facilitates self-actualization needs and denotes non-violence, meditation, kindliness, self-control, flexibility, creativity, intuition, self-sufficiency, strong willpower and selfless creativity (Daftuar \& Sharma, 1998; Srivastava, 2012). These attributes of Sattvics make people more self-compassionate and intrinsically motivated. The Rajas Guna nourishes self-esteem needs and symbolizes passion, activity, enthusiasm, interest, practical intelligence, moderate creativity, quick social and practical problem-solving abilities, variable willpower and strong desire, which may lead its bearers to become more inclined towards a performanceapproach (Daftuar \& Sharma, 1998; Srivastava, 2012). The Tamas Guna helps to satisfy only the basic needs and carries illusions, ambiguity, idleness, fantasy, persistence, cautiousness, apprehension, delusion, miscomprehension, low level of competitiveness, weak willpower, conformity to group norms, sensuous pleasure-seeking and revenge (Daftuar \& Sharma, 1998; Srivastava, 2012). These qualities of Tamasics make people more inclined to performance-avoidance. In essence, the spiritual, active and material qualities of Sattva, Rajas and Tamas Gunas, respectively, have been suggested to be responsible for their differential associations and contributions to the various life outcomes (Srivastava, 2012). The Sattvics, Rajasics and Tamasics also differ in their learning mechanisms. For a Sattvic, learning occurs through vicarious, trial and error, cognitive, single-trial or insight methods, whereas instrumental and contiguity mechanisms are involved in the learning process of the Rajasic and the Tamasic, respectively (Daftuar \& Sharma, 1998). These unique features of the three Gunas make them relevant to understand well-being and other life outcomes of individuals (Puta \& Sedlmeier, 2014).

The factor analysis also evinced the empirical validity of the two-factor structure of the self-compassion measure developed by Neff (2003b). This finding has been mirrored in some recent studies across populations and cultures which have posited that positive dimensions of self-compassion (selfkindness, common humanity and mindfulness) were more relevant to understand positive life outcomes while the negative dimensions (self-judgement, isolation and over-identification) appeared to be linked 
with psychopathological symptoms (Muris et al., 2018; Muris \& Otgaar, 2020; Pandey et al., 2019). Their differential nature of relationships and predictive strengths for the three-goal orientations in the present study provide further support to this argument. Thus, the findings suggest that the present self-compassion measure needs reconstruction and fresh standardization.

The findings showed that positive self-compassion was positively associated with mastery and negatively with performance goals. The researchers have suggested that positive self-compassion involves lesser fear of failure, greater perceived competence, emotional positive self-attitude, detachment from performance evaluations, self-worth, failure as a learning opportunity, a balanced perspective on shortcomings, positive perceptions of abilities, self-determination, emotional intelligence (the ability to experience one's feelings with clarity and to repair and regulate negative mood states) and adaptive emotion-focused coping strategies (Al-Awamleh, 2020; Neff et al., 2005, 2020; Parry, 2017). On the other hand, negative self-compassion involves emotional reactions, ruminative behaviour and avoidance-oriented strategies (Muris \& Otgaar, 2020; Neff et al., 2005). Positive selfcompassion was negatively related to and predicted performance-approach and avoidance goals while negative self-compassion was linked positively with and predicted performance-avoidance goals and was correlated negatively with performance-approach goals, similar to the earlier findings (Akin, 2008). Positive self-compassion may contribute mastery as it promotes autonomy, competence, engagement and relatedness (Babenko et al., 2018; Ten Cate, Kusurkar, \& Williams, 2011). Also, it may enhance perseverance of effort, self-worth, consistency of interest and self-efficacy, which, in turn, may promote mastery and performance-approach (Alhadabi \& Karpinski, 2020; Ståhlberg, Tuominen, Pulkka, \& Niemivirta, 2019; Suprayogi, Ratriana, \& Wulandari, 2019). Also, positive self-compassion facilitated acceptance of regretted experiences and adaptive emotional responses (Zhang \& Chen, 2016), reduced ego-threat, high self-worth and positive attributions (Shimizu, Niiya, \& Shigemasu, 2016) and increased self-improvement motivation (Breines \& Chen, 2012).

Mastery orientation involves curiosity, the desire to develop skills, master tasks and understand new materials, internal standards for achievement, effort, appropriate attributions for success and failure, and acceptance of mistakes as part of the learning process (common humanity), higher levels of intrinsic motivation, greater effort and persistence at tasks, willingness to seek help and high levels of intrinsic motivation (Elliot \& Harackiewicz, 1996), and enjoying and having satisfying life experiences and a greater sense of autonomy (Ryan \& Deci, 2000). These attributes of mastery may be cultivated and nourished more by the Sattvic Guna and positive selfcompassion.

Performance-approach refers to the tendency of individuals to outperform others to show competence, self-worth, ability attributions for success and failure and to evaluate their ability through social comparisons with others. It increases intrinsic motivation, greater effort and more persistence at tasks on one hand and shows an unwillingness to seek help, anxiety and disruptive behaviours on the other (Harackiewicz, Barron, \& Elliot, 1998). It also reflects superiority to others and fear of failure (Elliot \& Church, 1997), and feelings of self-centeredness, disconnection from others, prejudice and violence towards ego-threatening objects (Baumeister, Smart, $\&$ Boden, 1996). These features of performance-approach may naturally be found to remain close to the different degrees of the Sattva and Rajas Gunas, and positive self-compassion.

Negative self-compassion denotes self-judgment, isolation and over-identification, which are characterized by a critical attitude and harsh treatment towards self, intolerance towards negative traits of self, self-depreciation, self-comparison, thinking about others, feeling of loneliness during failure in important domains of life, indulgence in negative habits, feeling of inferiority and over-identification and maximization of events (Neff, 2003b). With these, negative self-compassion may promote a conditional attitude, perfectionism and procrastination, which may harm positive progression (Flett \& Hewitt, 2014). Performance-avoidance refers to the avoidance of situations of failures, incompetence, lower levels of intrinsic motivation, learned helplessness, disorganized efforts, an unwillingness to seek help and high levels of anxiety (Linnenbrink \& Pintrich, 2002; Ryan, Pintrich, \& Midgley, 2001). Both types of performance goals involve fear of failure (Elliot, 1999). These qualities of performance goals may be argued to make them closely linked with the Tamas Guna and negative self-compassion.

The path analysis evinced the significance of the interplay between the Triguna personality model and the two-factor conceptualization of the existing Self-Compassion Scale (Neff, 2003b) and their direct and indirect effects on the three academic goal orientations. In essence, self-compassion comprises enhanced perceived competence and lesser fear of failure, which may facilitate its link with mastery goals. Self-compassion also helps to avoid harsh self-judgement and increases self-confidence to learn and lowers failure anxiety. In this way, it becomes associated with mastery goals. Thus, selfcompassion is very relevant to understand the dynamics of the motivational patterns underlying academic achievement (Neff et al., 2005, 2020). Selfcompassion also explains performance-avoidance as it generates a lesser fear of failure. In previous stud- 
ies, self-compassion was positively associated with perceived competence and negatively linked with the fear of failure whereas both of these were positively associated with the performance-approach goals (Elliot \& Church, 1997). It has been argued that a negative correlation of self-compassion with performance-approach goals is useful as the superiority over others that drives the individuals to adopt performance-approach goals symbolizes maladaptive behaviours such as self-centeredness, prejudice, violence and social withdrawal (Baumeister et al., 1996; Covington, 1992; Roeser, Midgley, \& Urdan, 1996). In this way the negative association of performanceapproach with self-compassion is beneficial (Neff et al., 2005, 2020).

In conclusion, the findings of the present study showed self-compassion to be closely associated with adaptive motivational patterns in academic contexts, which has also been reported by previous researchers (Neff et al., 2005, 2020; Pandey et al., 2019, 2020). The findings evinced that self-compassion may have facilitated the learning process by freeing the student participants from the unacceptable consequences of self-criticism, isolation and over-identification in the face of failures and inadequacies on one hand and may have provided them with a positive self-attitude, positive emotionality and logical mind through self-kindness, common humanity and emotional balance on the other. This constructive attitude towards the self has been suggested to help students focus on mastering tasks and keep a distance from worry about performance evaluations and failures in comparisons (Neff et al., 2005, 2020). The findings also demonstrated that Sattva, Rajas and Tamas Gunas enunciated in the ancient Indian knowledge system have significant implications for unearthing the nature and dynamics of self-compassion and motivational patterns (goal orientations) of the students. The findings also showed that the existing selfcompassion measure (Neff, 2003b) incorporates both positive and negative dimensions having dissimilar implications for the three dimensions of academic goal orientations.

\section{IMPLICATIONS AND FUTURE DIRECTIONS FOR RESEARCHERS}

The findings reflect a significant contribution to explicating the relationship among Triguna personality, self-compassion and academic goal orientations. Research on self-compassion is gaining greater importance among the researchers to uncover socio-cultural and cross-national differences. These new insights about the nature, genesis, expression and development of self-compassion of the student participants in terms of the Triguna personality model may have significant implications to understand human perfor- mance in organizations, workplace, educational institutions, family and relationships. Further research on these constructs will facilitate the professionals in clinical, educational and organizational settings. Further scientific investigation of these constructs will also help to identify and redress the historical imbalance between resources, opportunities and protective factors for the people.

The findings of the current study have helped to develop new insights regarding the nature and dynamics of Indian conceptualizations of personality and its association with self-compassion and academic goal orientations. To better understand its nature and implications for academic success and life in general, longitudinal and cross-cultural studies are needed. This study was correlational in nature. Future studies may employ qualitative methods or mixed methods to uncover the basic nature of Triguna personality, self-compassion and academic goal orientations, especially in Indian socio-cultural milieu. Unlike the present study, which employed a comparatively small sample to fulfil its objectives, future research may involve larger and diverse samples to enhance the generalizability of these findings. Future researchers may focus on the cultural mechanisms inherent in Triguna personality and self-compassion shaping academic goal orientations. Future researchers should also involve participants belonging to non-student populations.

\section{REFERENCES}

Agrawal, J. (2020). Änanda \& Sukha: Indian model of happiness \& its mental health implications. MindRxiv, preprint. https://doi.org/10.31231/osf.io/g6msr

Akin, A. (2008). Self-compassion and achievement goals: a structural equation modeling approach. Eurasian Journal of Educational Research, 31, 1-15. Al-Awamleh, A. (2020). The relationship between selfcompassion and academic achievement for sport science students. Annals of Applied Sport Science, 8, 1-7. https://doi.org/10.29252/aassjournal.823

Alhadabi, A., \& Karpinski, A. C. (2020). Grit, self-efficacy, achievement orientation goals, and academic performance in university students. International Journal of Adolescence and Youth, 25, 519-535. https://doi.org/10.1080/02673843.2019.1679202

Allen, A. B., Goldwasser, E. R., \& Leary, M. R. (2012). Self-compassion and well-being among older adults. Self and Identity, 11, 428-453. https://doi.org/ 10.1080/15298868.2011.595082

Allen, A. B., \& Leary, M. R. (2010). Self-compassion, stress, and coping. Social and Personality Psychology Compass, 4, 107-118. https://doi.org/10.1111/ j.1751-9004.2009.00246.x

Arimitsu, K. (2014). Development and validation of the Japanese version of the Self-Compassion Scale. 
Shinrigaku Kenkyu: The Japanese Journal of Psychology, 85, 50-59. https://doi.org/10.4992/jjpsy.85.50

Azizi, A., Mohammadkhani, P., Foroughi, A. A., Lotfi, S., \& Bahramkhani, M. (2013). The validity and reliability of the Iranian version of the Self-Compassion Scale. Practice in Clinical Psychology, 1, 149-155.

Babenko, O., Mosewich, A., Abraham, J., \& Lai, H. (2018). Contributions of psychological needs, selfcompassion, leisure-time exercise, and achievement goals to academic engagement and exhaustion in Canadian medical students. Journal of Educational Evaluation for Health Professions, 15, 2. https://doi.org/10.3352/jeehp.2018.15.2

Banerjee, R., Pathak, R., \& Mathur, G. (2020). Relationship between personality and job performance: Indian perspective of Triguna theory. International Journal of Business Excellence, 20, 122-129. https:// doi.org/10.1504/IJBEX.2020.104844

Barnard, L. K., \& Curry, J. F. (2011). Self-compassion: Conceptualizations, correlates, \& interventions. Review of General Psychology, 15, 289-303. https:// doi.org/10.1037/a0025754

Baumeister, R. F., Smart, L., \& Boden, J. M. (1996). Relation of threatened egotism to violence and aggression: The dark side of high self-esteem. Psychological Review, 103, 5-33. https://doi.org/10.1037/ 0033-295X.103.1.5

Behr, D. (2017). Assessing the use of back translation: The shortcomings of back translation as a quality testing method. International Journal of Social Research Methodology, 20, 573-584. https://doi.org/ 10.1080/13645579.2016.1252188

Bernard, T. (1996). Hindu philosophy. Delhi: Motilal Banarsidass.

Betal, C. (2015). Role of Trigunas in framing of personality. Indian Streams Research Journal, 5, 1-5.

Bhaktivedanta, A. C. (Ed.). (1994). Bhagavad-gītā as it is: With the original Sanskrit text, Roman transliteration, English equivalents, translation and elaborate purports. Alachua, FL: Bhaktivedanta Book Trust.

Blascovich, J., \& Tomaka, J. (1991). Measures of selfesteem. In J. P. Robinson \& P. R. Shaver (Eds.), Measures of personality and social psychological attitudes (pp. 115-160). Cambridge, MA: Academic Press.

Breines, J. G., \& Chen, S. (2012). Self-compassion increases self-improvement motivation. Personality and Social Psychology Bulletin, 38, 1133-1143. https://doi.org/10.1177/0146167212445599

Brislin, R.W. (1970). Back-translation for cross-cultural research. Journal of Cross-Cultural Psychology, 1, 185-216. https://doi.org/10.1177/1359104570001 00301

Castilho, P., Pinto-Gouveia, J., \& Duarte, J. (2015). Evaluating the multifactor structure of the long and short versions of the self-compassion scale in a clinical sample: Factor analysis of the long and short self-compassion scale. Journal of Clinical Psychology, 71, 856-870. https://doi.org/10.1002/jclp.22187
Cleare, S., Gumley, A., Cleare, C. J., \& O'Connor, R. C. (2018). An investigation of the factor structure of the self-compassion scale. Mindfulness, 9, 618-628. https://doi.org/10.1007/s12671-017-0803-1

Coopersmith, S. (1967). The antecedents of self-esteem. San Francisco, CA: W. H. Freeman.

Corr, P. J. (2008). The reinforcement sensitivity theory. In P. J. Corr (Ed.), The reinforcement sensitivity theory of personality (pp. 347-376). Cambridge: Cambridge University Press.

Costa, P. T., \& McCrae, R. R. (1992). NEO Personality Inventory-Revised (NEO PI-R). Odessa, FL: Psychological Assessment Resources.

Covington, M. V. (1992). Making the grade: a self-worth perspective on motivation and school reform. Cambridge: Cambridge University Press.

Daftuar, C. N., \& Sharma, R. (1998). Beyond Maslow: an Indian perspective of need-hierarchy. Journal of the Maharaja Sayajirao University of Baroda, 24, 1-8.

Damon, W. (1995). Greater expectations: Overcoming the culture of indulgence in America's homes and schools. New York: Free Press.

Das, D. G. (1999). The Vedic personality inventory. Durbuy: Bhaktivedanta College.

Dasgupta, S. (1961). A history of Indian philosophy. Cambridge: Cambridge University Press.

Datar, S., \& Murthy, C. V. (2019). Development of Mysore Triguna scale-short. Journal of Psychosocial Research, 14, 311-318. https://doi.org/10.32381/ JPR.2019.14.02.8

Dhulla, T. V. (2011). A new approach to Indian philosophy and personality - a study. Indian Journal of Applied Research, 4, 386-387. https://doi.org/ 10.15373/2249555X/MAY2014/115

Donald, S. (2016). Data screening using SPSS for beginner: Outliers, missing values and normality. Institute of Borneo Studies, UNIMAS. Retrieved from https://ir.unimas.my/id/eprint/12266/

Dreisoerner, A., Junker, N. M., \& van Dick, R. (2020). The relationship among the components of selfcompassion: A pilot study using a compassionate writing intervention to enhance self-kindness, common humanity, and mindfulness. Journal of Happiness Studies. https://doi.org/10.1007/s10902019-00217-4

Elliot, A. J. (1999). Approach and avoidance motivation and achievement goals. Educational Psychologist, 34, 169-189. https://doi.org/10.1207/s15326985ep3403_3

Elliot, A. J., \& Church, M. A. (1997). A hierarchical model of approach and avoidance achievement motivation. Journal of Personality and Social Psychology, 72, 218-232. https://doi.org/10.1037/0022-3514.72. 1.218

Elliot, A. J., \& Harackiewicz, J. M. (1996). Approach and avoidance achievement goals and intrinsic motivation: a mediational analysis. Journal of Personality and Social Psychology, 70, 461-475. https:// doi.org/10.1037/0022-3514.70.3.461 
Elliot, A. J., \& McGregor, H. A. (2001). A $2 \times 2$ achievement goal framework. Journal of Personality and Social Psychology, 80, 501-519. https://doi.org/10. 1037/0022-3514.80.3.501

Flett, G. L., \& Hewitt, P. L. (2014). A proposed framework for preventing perfectionism and promoting resilience and mental health among vulnerable children and adolescents. Psychology in the Schools, 51, 899-912. https://doi.org/10.1002/pits.21792

Garcia-Campayo, J., Navarro-Gil, M., Andrés, E., Montero-Marin, J., López-Artal, L., \& Demarzo, M. M. (2014). Validation of the Spanish versions of the long (26 items) and short (12 items) forms of the Self-Compassion Scale (SCS). Health and Quality of Life Outcomes, 12, 4. https://doi.org/10.1186/14777525-12-4

Harackiewicz, J. M., Barron, K. E., \& Elliot, A. J. (1998). Rethinking achievement goals: When are they adaptive for college students and why? Educational Psychologist, 33, 1-21. https://doi.org/10.1207/ s15326985ep3301_1

Harackiewicz, J. M., Barron, K. E., Pintrich, P. R., Elliot, A. J., \& Thrash, T. M. (2002). Revision of achievement goal theory: Necessary and illuminating. Journal of Educational Psychology, 94, 638645. https://doi.org/10.1037/0022-0663.94.3.638

Hewitt, J. P. (2005). The social construction of selfesteem. In C. R. Snyder \& S. J. Lopez (Eds.), Handbook of positive psychology (pp. 135-148). New York: Oxford University Press.

Ilavarasu, J. V., Mohan, S., \& Hankey, A. (2013). Triguna as personality concept: Guidelines for empirical research. International Journal of Yoga Philosophy, Psychology and Parapsychology, 1, 15. https://doi.org/10.4103/2347-5633.123287

Judge, T. A., \& Ilies, R. (2002). Relationship of personality to performance motivation: a meta-analytic review. Journal of Applied Psychology, 87, 797-807. https://doi.org/10.1037/0021-9010.87.4.797

Khanna, P., Singh, K., Singla, S., \& Verma, V. (2013). Relationship between Triguna theory and well-being indicators. International Journal of Yoga - Philosophy, Psychology and Parapsychology, 1, 69-74. https://doi.org/10.4103/2347-5633.157888

Krishnamurthy, V. S. (1999). Spiritualise to lead a stressfree life. Chennai: T. R. Publications.

Leary, M. R., Tate, E. B., Adams, C. E., Allen, A. B., \& Hancock, J. (2007). Self-compassion and reactions to unpleasant self-relevant events: The implications of treating oneself kindly. Journal of Personality and Social Psychology, 92, 887-904. https:// doi.org/10.1037/0022-3514.92.5.887

Linnenbrink, E. A., \& Pintrich, P. R. (2002). Achievement goal theory and affect: an asymmetrical bidirectional model. Educational Psychologist, 37, 69-78. https://doi.org/10.1207/S15326985EP3702_2

Lopez, A., Sanderman, R., Ranchor, A. V., \& Schroevers, M. J. (2018). Compassion for others and self- compassion: Levels, correlates, and relationship with psychological well-being. Mindfulness, 9, 325-331. https://doi.org/10.1007/s12671-017-0777-z Lyubomirsky, S., \& Nolen-Hoeksema, S. (1995). Effects of self-focused rumination on negative thinking and interpersonal problem solving. Journal of Personality and Social Psychology, 69, 176-190. https://doi.org/10.1037//0022-3514.69.1.176

MacBeth, A., \& Gumley, A. (2012). Exploring compassion: a meta-analysis of the association between self-compassion and psychopathology. Clinical Psychology Review, 32, 545-552. https://doi.org/10. 1016/j.cpr.2012.06.003

McMillan, J. H., Singh, J., \& Simonetta, L. G. (1994). The tyranny of self-oriented self-esteem. Educational Horizons, 72, 141-145.

Midgley, C., Kaplan, A., Middleton, M., Maehr, M. L., Urdan, T., Anderman, L. H., Anderman, E., \& Roeser, R. (1998). The development and validation of scales assessing students' achievement goal orientations. Contemporary Educational Psychology, 23, 113-131. https://doi.org/10.1006/ceps.1998.0965

Montero-Marin, J., Kuyken, W., Crane, C., Gu, J., Baer, R., Al-Awamleh, A. A., Akutsu, S., Araya-Véliz, C., Ghorbani, N., Chen, Z. J., Kim, M. S., Mantzios, M., Rolim dos Santos, D. N., Serramo López, L. C., Teleb, A. A., Watson, P. J., Yamaguchi, A., Yang, E., \& García-Campayo, J. (2018). Self-compassion and cultural values: a cross-cultural study of self-compassion using a multitrait-multimethod (MTMM) analytical procedure. Frontiers in Psychology, 9, 2638. https://doi.org/10.3389/fpsyg.2018.02638

Muris, P., \& Otgaar, H. (2020). The process of science: a critical evaluation of more than 15 years of research on self-compassion with the Self-Compassion Scale. Mindfulness, 11, 1469-1482. https://doi. org/10.1007/s12671-020-01363-0

Muris, P., Otgaar, H., \& Petrocchi, N. (2016). Protection as the mirror image of psychopathology: Further critical notes on the self-compassion scale. Mindfulness, 7, 787-790. https://doi.org/10.1007/s12671-0160509-9

Muris, P., \& Petrocchi, N. (2017). Protection or vulnerability? A meta-analysis of the relations between the positive and negative components of self-compassion and psychopathology. Clinical Psychology \& Psychotherapy, 24, 373-383. https://doi.org/ 10.1002/cpp.2005

Muris, P., van den Broek, M., Otgaar, H., Oudenhoven, I., \& Lennartz, J. (2018). Good and bad sides of self-compassion: a face validity check of the Self-Compassion Scale and an investigation of its relations to coping and emotional symptoms in non-clinical adolescents. Journal of Child and Family Studies, 27, 2411-2421. https://doi.org/10.1007/ s10826-018-1099-z

Neff, K. D. (2003a). Self-compassion: an alternative conceptualization of a healthy attitude toward 
oneself. Self and Identity, 2, 85-101. https://doi.org/ 10.1080/15298860309032

Neff, K. D. (2003b). The development and validation of a scale to measure self-compassion. Selfand Identity, 2, 223-250. https://doi.org/10.1080/15298860309027

Neff, K. D., Bluth, K., Tóth-Király, I., Davidson, O., Knox, M. C., Williamson, Z., \& Costigan, A. (2020). Development and validation of the Self-Compassion Scale for Youth. Journal of Personality Assessment. https://doi.org/10.1080/00223891.2020.1729774

Neff, K. D., Hsieh, Y. P., \& Dejitterat, K. (2005). Selfcompassion, achievement goals, and coping with academic failure. Self and Identity, 4, 263-287. https://doi.org/10.1080/13576500444000317

Neff, K. D., Kirkpatrick, K. L., \& Rude, S. S. (2007a). Self-compassion and adaptive psychological functioning. Journal of Research in Personality, 41, 139154. https://doi.org/10.1016/j.jrp.2006.03.004

Neff, K. D., \& Pommier, E. (2013). The relationship between self-compassion and other-focused concern among college undergraduates, community adults, and practicing meditators. Self and Identity, 12, 160176. https://doi.org/10.1080/15298868.2011.649546

Neff, K. D., Rude, S. S., \& Kirkpatrick, K. L. (2007b). An examination of self-compassion in relation to positive psychological functioning and personality traits. Journal of Research in Personality, 41, 908-916. https://doi.org/10.1016/j.jrp.2006.08.002

Neff, K. D., Whittaker, T. A., \& Karl, A. (2017). Examining the factor structure of the self-compassion scale in four distinct populations: Is the use of a total scale score justified? Journal of Personality Assessment, 99, 596-607. https://doi.org/10.1080/ 00223891.2016.1269334

Pandey, R., Tiwari, G. K., Pandey, R., Mandal, S. P., Mudgal, S., Parihar, P., Rai, P. K., Tiwari, A. S., \& Shukla, M. (2020). The relationship between self-esteem and self-forgiveness: Understanding the mediating role of positive and negative selfcompassion. Authorea, preprint. https://doi.org/ 10.22541/au.158981530.01103201

Pandey, R., Tiwari, G. K., Parihar, P., \& Rai, P. K. (2019). Positive, not negative, self-compassion mediates the relationship between self-esteem and well-being. Psychology and Psychotherapy: Theory, Research and Practice. https://doi.org/10.1111/papt.12259

Parry, E. (2017). Self-compassion and the pursuit of personal goals. Retrieved from https://ore.exeter. ac.uk/repository/handle/10871/28999

Pfattheicher, S., Geiger, M., Hartung, J., Weiss, S., \& Schindler, S. (2017). Old wine in new bottles? The case of self-compassion and neuroticism: Selfcompassion and neuroticism. European Journal of Personality, 31, 160-169. https://doi.org/10.1002/ per.2097

Planet Ayurveda (2020). Triguna theory of Ayurveda. Retrieved from https://www.planetayurveda.com/ triguna-theory-of-ayurveda/
Potter, K. H. (Ed.). (1970). The encyclopedia of Indian philosophies. Delhi: Motilal Banarsidass.

Puta, M., \& Sedlmeier, P. (2014). The concept of TriGuna: a working model. In S. Schmidt \& H. Walach (Eds.), Meditation - neuroscientific approaches and philosophical implications (Vol. 2, pp. 317-364). Cham: Springer.

Pyszczynski, T., Greenberg, J., Solomon, S., Arndt, J., \& Schimel, J. (2004). Why do people need selfesteem? A theoretical and empirical review. Psychological Bulletin, 130, 435-468. https://doi.org/ 10.1037/0033-2909.130.3.435

Rai, P. K., \& Tiwari, G. K. (2019). Self-compassion and positive mental health. In S. Ojha, M. Asthana, \& U. Ojha, Spirituality \& health: Emerging issues (pp. 175-201). Delhi: Shree Publishers \& Distributors.

Revelle, W. (1995). Personality processes. Annual Review of Psychology, 46, 295-328. https://doi. org/10.1146/annurev.ps.46.020195.001455

Roeser, R. W., Midgley, C., \& Urdan, T. C. (1996). Perceptions of the school psychological environment and early adolescents' psychological and behavioral functioning in school: The mediating role of goals and belonging. Journal of Educational Psychology, 88, 408-422. https://doi.org/10.1037/00220663.88.3.408

Rosenberg, M. (1965). Society and the adolescent selfimage. Princeton, NJ: Princeton University Press.

Rosenberg, M. (2016). Society and the adolescent selfimage. Princeton, NJ: Princeton University Press.

Rubin, K. H., \& Coplan, R. J. (2004). Paying attention to and not neglecting social withdrawal and social isolation. Merrill-Palmer Quarterly, 50, 506-534. https://doi.org/10.1353/mpq.2004.0036

Ryan, A. M., Pintrich, P. R., \& Midgley, C. (2001). Avoiding seeking help in the classroom: Who and why? Educational Psychology Review, 13, 93-114. https://doi.org/10.1023/A:1009013420053

Ryan, R. M., \& Deci, E. L. (2000). Intrinsic and extrinsic motivations: Classic definitions and new directions. Contemporary Educational Psychology, 25, 54-67. https://doi.org/10.1006/ceps.1999.1020

Ryan, R. M., \& Deci, E. L. (2004). Avoiding death or engaging life as accounts of meaning and culture: Comment on Pyszczynski et al. (2004). Psychological Bulletin, 130, 473-477. https://doi.org/10.1037/00332909.130.3.473

Seligman, M. E. P., Reivich, K., Jaycox, L., \& Gillham, J. (1996). The optimistic child. New York: Harper Perennial.

Sharma, M. P., Salvi, D., \& Sharma, M. K. (2012). Sattva, Rajas and Tamas factors and quality of life in patients with anxiety disorders: a preliminary investigation. Psychological Studies, 57, 388-391. https://doi.org/10.1007/s12646-012-0167-5

Shilpa, S., \& Venkatesha Murthy, C. G. (2011). Understanding personality from Ayurvedic perspec- 
tive for psychological assessment: a case. AYU An International Quarterly Journal of Research in Ayurveda, 32, 12-19. https://doi.org/10.4103/09748520.85716

Shilpa, S., \& Venkatesha Murthy, C. G. (2012). Development and standardization of Mysore Triguna scale. SAGE Open, 2, 1-10. https://doi.org/ $10.1177 / 2158244012436564$

Shimizu, M., Niiya, Y., \& Shigemasu, E. (2016). Achievement goals and improvement following failure: Moderating roles of self-compassion and contingency of self-worth. Self and Identity, 15, 107-115. https://doi.org/10.1080/15298868.2015.1084371

Singh, K., Jain, A., Kaur, J., Junnarkar, M., \& Slezackova, A. (2016). Cross-cultural differences on Gunas and other well-being dimensions. Asian Journal of Psychiatry, 24, 139-146. https://doi.org/10.1016/j. ajp.2016.09.001

Singh, K., \& Slezáčková, A. (2013). Relationship between Gunas and mental health, flourishing, positive and negative experience: an Indian and Western perspective. Retrieved from https://www.muni.cz/ en/research/publications/1111046

Sirois, F. M. (2020). The association between selfcompassion and self-rated health in 26 samples. BMC Public Health, 20, 74. https://doi.org/10.1186/ s12889-020-8183-1

Sirois, F. M., Molnar, D. S., \& Hirsch, J. K. (2015). Self-compassion, stress, and coping in the context of chronic illness. Self and Identity, 14, 334-347. https://doi.org/10.1080/15298868.2014.996249

Sitamma, M., Sridevi, K., \& Krishna Rao, P. V. (1995). Three Gunas and cognitive characteristics: a study of field dependence-independence and perceptual acuity. Journal of Indian Psychology, 13, 13-20.

Srivastava, K. (2012). Concept of personality: Indian perspective. Industrial Psychiatry Journal, 21, 8993. https://doi.org/10.4103/0972-6748.119586

Ståhlberg, J., Tuominen, H., Pulkka, A. T., \& Niemivirta, M. (2019). Maintaining the self? Exploring the connections between students' perfectionistic profiles, self-worth contingency, and achievement goal orientations. Personality and Individual Differences, 151, 109495. https://doi.org/10.1016/j. paid.2019.07.005

Suprayogi, M. N., Ratriana, L., \& Wulandari, A. P. J. (2019). The interplay of academic efficacy and goal orientation toward academic achievement. Journal of Physics: Conference Series, 1175, 012132. https://doi.org/10.1088/1742-6596/1175/1/012132

Ten Cate, O. Th. J., Kusurkar, R. A., \& Williams, G. C. (2011). How self-determination theory can assist our understanding of the teaching and learning processes in medical education. Medical Teacher, 33, 961973. https://doi.org/10.3109/0142159X.2011.595435

Thurackal, J. T., Corveleyn, J., \& Dezutter, J. (2016). Personality and self-compassion: Exploring their relationship in an Indian context. European Journal of
Mental Health, 11, 18-35. https://doi.org/10.5708/ EJMH.11.2016.1-2.2

Tiwari, G. K., Pandey, R., Rai, P. K., Pandey, R., Verma, Y., Parihar, P., Ahirwar, G., Tiwari, A. S., \& Mandal, S. P. (2020). Self-compassion as an intrapersonal resource of perceived positive mental health outcomes: a thematic analysis. Mental Health, Religion \& Culture. https://doi.org/10.1080/13674676.2020.17 74524

Tóth-Király, I., \& Neff, K. D. (2020). Is self-compassion universal? Support for the measurement invariance of the self-compassion scale across populations. Assessment. https://doi.org/10.1177/1073191120926232

Verma, Y., \& Tiwari, G. K. (2017). Self-compassion as the predictor of flourishing of the students. The International Journal of Indian Psychology, 4, 10-29. https://doi.org/10.25215/0403.122

Werner, K. H., Jazaieri, H., Goldin, P. R., Ziv, M., Heimberg, R. G., \& Gross, J. J. (2012). Self-compassion and social anxiety disorder. Anxiety, Stress, and Coping, 25, 543-558. https://doi.org/10.1080/10615 806.2011 .608842

Williams, J. G., Stark, S. K., \& Foster, E. E. (2008). The relationships among self-compassion, motivation, and procrastination. American Journal of Psychological Research, 4, 37-44.

Wolf, D. B. (1998). The Vedic personality inventory: a study of the Gunas. Journal of Indian Psychology, $16,26-43$.

Zhang, J. W., \& Chen, S. (2016). Self-compassion promotes personal improvement from regret experiences via acceptance. Personality and Social Psychology Bulletin, 42, 244-258. https://doi.org/ $10.1177 / 0146167215623271$

Zuroff, D. C., Igreja, I., \& Mongrain, M. (1990). Dysfunctional attitudes, dependency, and self-criticism as predictors of depressive mood states: a 12-month longitudinal study. Cognitive Therapy and Research, 14, 315-326. https://doi.org/10.1007/ BF01183999 